\title{
Comparison of corneal power obtained from VERION image-guided surgery system and four other devices
}

This article was published in the following Dove Press journal:

Clinical Ophthalmology

12 July 2017

Number of times this article has been viewed

\author{
Hung-Yuan Lin ${ }^{1, *}$ \\ Hsin-Yang Chen ${ }^{1,2, *}$ \\ Han Bor Fam ${ }^{3}$ \\ Ya-Jung Chuang' \\ Ronald Yeoh ${ }^{4}$ \\ $\mathrm{Pi}$-Jung Lin $^{5}$
}

'Universal Eye Center, Zhongli Branch, Zhongli County, TaoYuan City, Taiwan, Republic of China; ${ }^{2}$ Ophthalmology Department, Ningbo First Hospital, Ningbo, Zhejiang Province, People's Republic of China; ${ }^{3}$ Ophthalmology Department, Tan Tock Seng Hospital, Jalan Tan Tock Seng, ${ }^{4}$ Ophthalmology Department, Eye and Retina Surgeons, Camden Medical Centre, Singapore;

${ }^{5}$ Universal Eye Center, Xinnan Branch,

Taipei City, Taiwan, Republic of China

*These authors contributed equally to this work
Correspondence: Hung-Yuan Lin Universal Eye Center, Zhongli Branch, No 212, ZhongShan Road, Zhongli County, TaoYuan City 32044, Taiwan, Republic of China

Tel +886955337370

Email hylinmd@ms|4.hinet.net
Purpose: To assess the corneal keratometric values obtained using the VERION image-guided surgery system and other devices.

Methods: This study evaluated the right eyes of 115 cataract patients before intraocular lens (IOL) implantation through consecutive tests using 5 devices: VERION Reference Unit, Placidobased corneal topography (OPD-Scan III), monochromatic light-emitting diodes (LenStar LS900 and AL-Scan), and rotary prism technology (auto kerato-refractometer KR-8800). Analyzed parameters were corneal steep and flat keratometric values ( $\mathrm{Ks}$ and $\mathrm{Kf}$ ) and corneal astigmatism and axis. These parameters were evaluated using the one-sample two-tailed $t$-test and the 95\% limits of agreement (95\% LOAs) between the devices.

Results: The mean corneal cylinder value measurements were $-0.97 \pm 0.63 \mathrm{D},-0.88 \pm$ $0.60 \mathrm{D},-0.90 \pm 0.69 \mathrm{D},-0.90 \pm 0.67 \mathrm{D}$, and $-0.83 \pm 0.60 \mathrm{D}$ with VERION, LenStar, AL-Scan (2.4 mm), OPD III, and KR-8800, respectively. Only KR-8800 showed a significant difference from VERION in the corneal cylinder value $(P<0.05)$. The mean differences in the $\mathrm{Kf}$ and Ks of VERION compared to those of OPD III were $0.18 \pm 0.45 \mathrm{D}$ and $0.17 \pm 0.38 \mathrm{D}(P<0.05)$, respectively. The $95 \%$ LOAs of Bland-Altman analysis for the corneal astigmatism axis of the VERION with LenStar, AL-Scan (2.4 mm), OPD III, and KR-8800 were $-26.25^{\circ}$ to $58.71^{\circ},-20.61^{\circ}$ to $47.44^{\circ},-25.03^{\circ}$ to $58.98^{\circ}$, and $-27.85^{\circ}$ to $65.17^{\circ}$, respectively.

Conclusion: None of the VERION parameters were significantly different from those of AL-Scan and LenStar. AL-Scan (2.4 mm zone) was especially similar to VERION. Wide LOAs are potential contributors to axis error in patients with toric IOL implants.

Keywords: phacoemulsification, toric IOL, corneal astigmatism, surgical induced astigmatism, image-guided surgery system

\section{Introduction}

Recent applications and developments have increased the accuracy of preoperative corneal shape and refractive power evaluations prior to phacoemulsification with intraocular lens (IOL) implantation. ${ }^{1,2}$ The toric IOL has been shown to have substantial efficacy in correcting astigmatism. ${ }^{3}$ Accurate keratometry values (K-values) can be used as part of surgical planning for corneal incision design, astigmatic keratotomy (AK), the management of surgery-induced astigmatism (SIA), and correcting postoperative residual astigmatism. ${ }^{4,5}$ Several previous studies have compared corneal astigmatism measurements obtained using a range of keratometers. ${ }^{1,6-12}$

The VERION image-guided system (Alcon, Fort Worth, TX, USA) is a new surgical-assisted platform that combines the use of the VERION Reference Unit and enables the measurement of K-values. Preoperative corneal curvature data can be 
integrated with anterior segment imaging for intraoperative registration. Further, real-time visual image marking under microscopy can facilitate the placement of toric IOL during surgery. ${ }^{13}$ Corneal surface data may also be combined with the use of the femtosecond cataract surgery platform, LenSx (Alcon), for corneal incision design and limbal relaxing incisions.

The main aim of this study was to assess the utility of the VERION Reference Unit (Alcon) and to perform comparisons with commonly used keratometers containing monochromatic light-emitting diodes (LEDs) (LenStar LS900; Haag-Streit, Switzerland, and AL-Scan Optical Biometer; Nidek, Japan), topographers based on the use of Placido rings (OPD-Scan III; Nidek), and a rotary prism system (auto kerato-refractometer KR-8800; Topcon, Japan).

\section{Materials and methods}

This retrospective study included cataract patients from the general population recruited from the private Universal Eye Center in Zhong-Li, Taiwan. Before phacoemulsification with IOL implantation surgery, corneal curvature measurements for the right eye (115 eyes) of all subjects obtained with 5 different instruments were compared: the VERION Reference Unit, a LenStar LS900 optical low-coherence reflectometer (OLCR), an AL-Scan Optical Biometer, the Placido disk topography OPD-Scan III, and the auto keratorefractometer KR-8800. All examinations were performed under the same low-light conditions. The data captures for the 5 devices were obtained after ensuring a lack of head tilt, and the eye was aligned to the visual axis by a central fixation target or light spot.

All patients were informed about the risks and benefits prior to cataract surgery and provided written informed consent in accordance with the institutional guidelines and the Declaration of Helsinki regarding human research. This study was approved by the institutional review board of Antai Tian-Sheng Memorial Hospital (No 15-033-B1).

Patients with anterior segment disease, high or special ametropia, corneal irregular astigmatism, and pterygium were excluded from this study. As all devices were based on eye gaze, we further excluded individuals with severe refractive medium opacity, macular degeneration, retinal diseases, nystagmus, and poor cooperation, which can affect measurement accuracy. ${ }^{14}$ Data sets were excluded if data for any of the parameters were not available. All operations were performed by the same skilled physician, and all data were obtained from the anterior corneal surface. Measured parameters included the flattest keratometry (Kf), steepest keratometry (Ks), and axis values presented as $\mathrm{Kf}, \mathrm{Ks}, \mathrm{Kf}$, and $\mathrm{Ks}$ axis.

\section{Devices}

The VERION image-guided surgery system was first evaluated in clinical trials in 2013. This system combines the preoperative measurement terminal VERION Reference Unit, which enables the measurement of keratometry parameters and anterior segment imaging-based biometric identification. The system is able to adjust focus for corneal astigmatism using 3 infrared projections on to the front corneal surface. The combination of 12 corneal-reflected light spots from monochromatic LED sources allows for a measurement area with a diameter of $2.8 \mathrm{~mm}$.

The LenStar LS900 system also has an all-in-one integrated design $^{15}$ and is based on OLCR with an $820 \mathrm{~nm}$ wavelength super luminescent diode laser light source at a $20 \mu \mathrm{m}-30 \mathrm{~nm}$ spectral coherence width. This device enables the measurement of corneal diameter (white-to-white [WTW]), central corneal thickness (CCT), anterior chamber depth (ACD), pupil diameter (PD), and axial length (AL). Keratometry uses 2 concentric rings of $32(2 \times 16)$ light points that are reflected off the anterior corneal surface, with each zone covering an area of $1.65 \mathrm{~mm}$ by $2.3 \mathrm{~mm}$. The use of 2 concentric rings allows high accuracy to be maintained even in patients with poor gaze. ${ }^{16}$

The AL-Scan is a device with an all-in-one integrated design that uses partial coherence interferometry technology for corneal keratometry. This device also enables the measurement of WTW, CCT, ACD, PD, and AL values. Keratometry is obtained over a corneal diameter range of 2.4-3.3 mm, with 360 light spots reflected off and around the central cornea using monochromatic LEDs.

The OPD III scan device provides keratometry functions, anterior corneal shape measurement for corneal diameters of $3.0 \mathrm{~mm}$, and K-values calculated as average Sim-K-values (simulated keratometry). Placido disk topography is provided by 33 blue rings with 11,880 data points. All device specifications discussed in this article refer to data provided in official information documents.

The KR-8800 auto kerato-refractometer (Topcon) provides keratometry measurements for corneal diameters ranging from $3.0 \mathrm{~mm}$ to $7.7 \mathrm{~mm}$ according to the presence of anterior corneal astigmatism, with $\mathrm{K}$-values and corneal curvatures obtained over a range from $5.00 \mathrm{~mm}$ to $10.00 \mathrm{~mm}$ (0.01 mm, step display). This device relies on the definition of the steep and flat meridian cylinder axes set at $90^{\circ}$ to each other. Corneal curvature radius measurements are performed using a 4-point-based ring-shape (symmetric spherocylindrical shape) light pattern projected on to the anterior surface of the cornea. Rotary prism technology allows unparalleled image analysis in the infrared range. 
Auto kerato-refractometry is a common method used for evaluating clinical K-values.

\section{Statistical analyses}

For all devices, K-values were calculated using the same corneal refractive index $(n=1.3375)$. The following parameters were included in this analysis: $\mathrm{Kf}, \mathrm{Ks}$, $\mathrm{Kf}$ axial, $\mathrm{Ks}$ axial, corneal astigmatism, $\mathrm{Kf}-\mathrm{Ks}$, and average keratometry calculated as ave $\mathrm{K}=(\mathrm{Kf}+\mathrm{Ks}) / 2$. The statistical significance of the inter-device (VERION and the other 4 devices) differences in corneal K-reading parameters was evaluated with the one-sample two-tailed $t$-test. The correlation coefficient was also calculated using Pearson's or Spearman's correlation coefficients analysis. In addition, $\mathrm{K}$ readings were recorded in diopters for auto kerato-refractometry as 337.5/(radius of curvature in $\mathrm{mm}$ ).

Before analyzing the astigmatic axis differences, the angle value differences were corrected and the relative angle difference values were defined for the purpose of quantification and calculation (Figure 1). The minimum angle difference between VERION and the other devices was calculated using the following formula:

$$
\begin{aligned}
& A_{\text {dif }}=180^{\circ}-\left|A_{1}-A_{2}\right|, \\
& \text { if }\left|A_{1}-A_{2}\right| \geq 90^{\circ} ; A_{\text {dif }}=\left|A_{1}-A_{2}\right|
\end{aligned}
$$

The $A_{\text {dif }}$ is the angle of the cylinder axis difference; $A_{1}$ is the cylinder axis values from Device 1 , while $\mathrm{A}_{2}$ is the cylinder axis values from Device 2. Further, the axis values for the Bland-Altman plot $^{17}$ were recalculated before analysis of the astigmatic axis, with $180^{\circ}$ set as $0^{\circ}, 175^{\circ}$ as $-5^{\circ}$, and $15^{\circ}$ as $195^{\circ}$ or $-165^{\circ}\left(\mathrm{A}-180^{\circ}\right.$ or $\left.\mathrm{A}+180^{\circ}\right)$. In the one-sample $t$-test analysis, the data were processed in the same manner.

The Kf, Kf axis, Ks, Ks axis, cylinder, and ave K were presented as the mean and standard deviations (SDs). Oneway analysis of variance was performed to compare the differences between the devices, and the Bonferroni posthoc test was used for multiple comparisons. The coefficient of variation $(\mathrm{CV})$ was used to identify the variability of the differences between VERION and the other devices. Bland-Altman analysis ${ }^{17}$ was performed to assess the level of agreement between VERION and each device. The plots of the differences between the 2 measurement techniques against the average values obtained from each technique were used to assess the agreement between the VERION and other devices. The range of agreement in the Bland-Altman plot was defined as the $95 \%$ limit for each comparison (mean $\pm 1.96 \mathrm{SD}$ of the difference).

Statistical analyses were performed with IBM SPSS statistical software version 22 for Windows (IBM Corporation, Armonk, NY, USA). Two-tailed $P<0.05$ indicated statistical significance.

\section{Results}

Data were analyzed and reviewed from 115 cataract patients who had measurements taken between October 2014 and

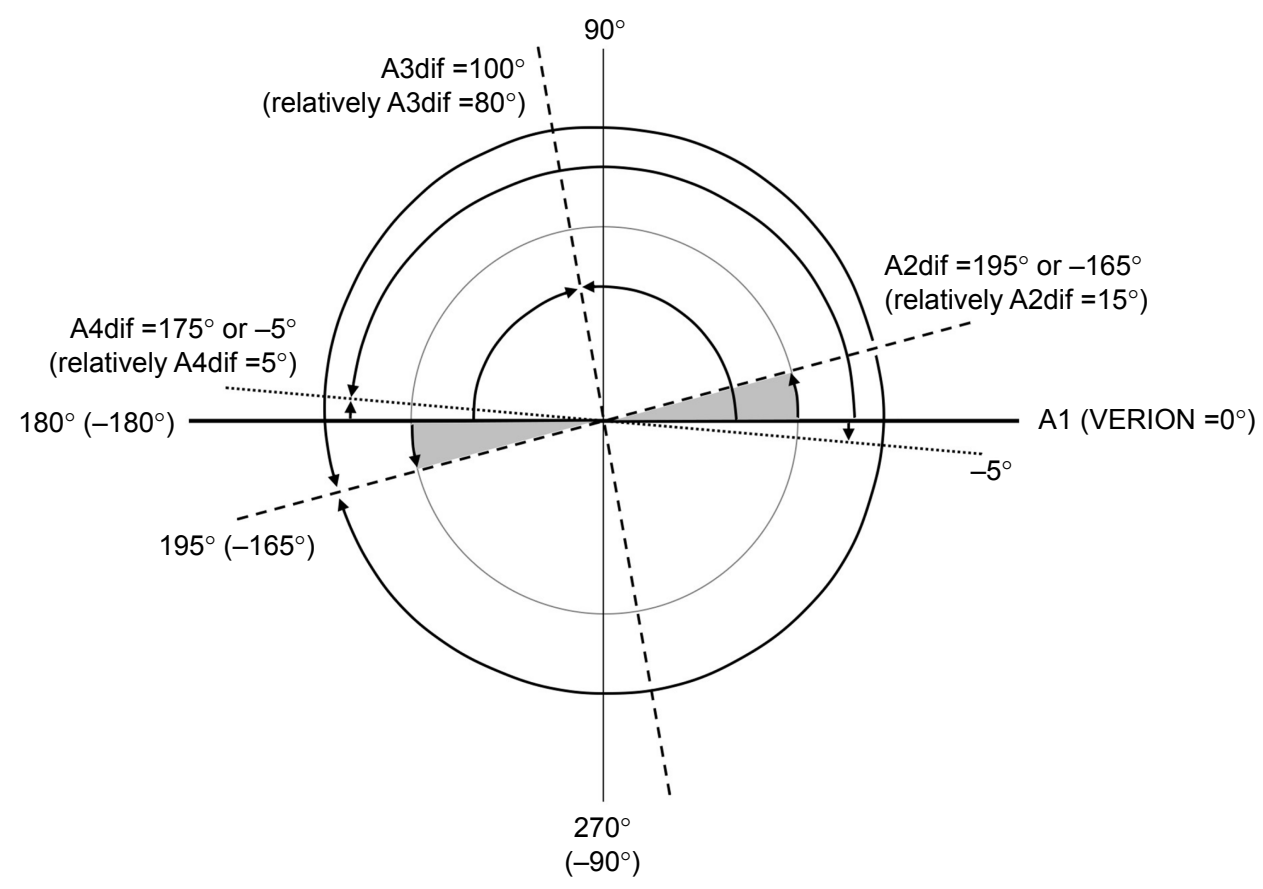

Figure I Examples of relative angle differences. 
Table I Comparability of corneal cylinder and astigmatic axis ( $\mathrm{Kf}$ axis) values of all patients with 5 different devices displayed as mean \pm SD

\begin{tabular}{llll}
\hline Device & Method & Measuring field & $\begin{array}{l}\text { Keratometry reading of corneal } \\
\text { cylinder }\end{array}$ \\
\cline { 3 - 3 } & & Mean (D \pm SD @ Degrees \pm SD) \\
\hline Eye N=II5 & & $-0.97 \pm 0.63 @ 95.35 \pm 58.33$ \\
VERION & Monochromatic LEDs & $2.8 \mathrm{~mm}$ & $-0.88 \pm 0.60 @ 94.10 \pm 55.99$ \\
LenStar & Monochromatic LEDs & $1.65 \mathrm{~mm}$ and $2.3 \mathrm{~mm}$ & $-0.90 \pm 0.69 @ 93.79 \pm 55.95$ \\
AL-Scan $(2.4 \mathrm{~mm})$ & Monochromatic LEDs & $2.4 \mathrm{~mm}$ & $-0.90 \pm 0.67 @ 94.04 \pm 59.11$ \\
OPD III & Placido rings & $3.0 \mathrm{~mm}$ & $-0.83 \pm 0.60 @ 91.96 \pm 61.21$ \\
KR-8800 & Rotary prism system & $3.0 \mathrm{~mm}$ to $7.0 \mathrm{~mm}$ & \\
\hline
\end{tabular}

Abbreviations: Kf axis, flattest keratometry axis; SD, standard deviation; LEDs, light-emitting diodes.

December 2014. The final analysis was performed on 115 eyes, with all corneal data obtained from the right eye. The mean age of the patients included in the study was $62.80 \pm 10.91$ years (range, $32-90$ years). The mean corneal K-values obtained using the VERION image-guided surgery system were as follows: mean $\mathrm{Kf}, 43.89 \pm 1.59 \mathrm{D}$ with a mean axis of $95.35^{\circ} \pm 58.33^{\circ}$; mean Ks, $44.76 \pm 1.64 \mathrm{D}$ with a mean axis of $93.00^{\circ} \pm 55.19^{\circ}$; and mean corneal astigmatism (Kf-Ks), $-0.97 \pm 0.63 \mathrm{D}$.

\section{Analysis of power of corneal astigmatism (Kf-Ks)}

The mean corneal astigmatic powers measured with each device are shown in Table 1. The VERION system had slightly greater power values for corneal astigmatism than the other devices. The differences in corneal cylinder power between VERION and the other devices ranged from $0.06 \mathrm{D}$ to $0.14 \mathrm{D}$. However, there were no statistically significant differences in corneal astigmatism observed between VERION and LenStar, AL-Scan (2.4 mm), or OPD III devices. When comparing VERION with KR-8800, a larger difference in keratometric power was observed than in comparisons with the other devices. The mean difference in corneal astigmatism was $0.14 \pm 0.26 \mathrm{D}$, with a statistically significant difference $(t=-2.450 ; P<0.05)$.

Table 2 shows the corneal astigmatism differences between VERION and the other 4 devices. Compared to VERION, 74 eyes (64\%) measured with AL-Scan $(2.4 \mathrm{~mm})$ had corneal cylinder differences $<0.25 \mathrm{D}$ the $(0.25-0.50 \mathrm{D})$ and $(0.50-0.75 \mathrm{D})$ ranges showed $9 \%$ and $21 \%$, respectively.

Figure 2 shows the Bland-Altman plots for the agreements in corneal cylinder measurements between VERION and the other devices. A low to moderate level of agreement was observed between the 2 values form VERON and other devices based on the $95 \%$ limits of agreement (LOAs). The width of the $95 \%$ LOAs in corneal cylinder power ranged from 1.03 D to 1.24 D for the differences between VERION and the 4 devices. The narrowest width for the 95\% LOAs was between VERION and KR-8800 (1.03 D).

\section{Flattest and steepest keratometry analysis}

In this study, we compared the $\mathrm{Kf}, \mathrm{Ks}$, and ave $\mathrm{K}$ from VERION and 4 devices. The results are shown in Table 3. No statistically significant differences were found between VERION, LenStar, AL-Scan, and KR-8800. However, the mean differences in $\mathrm{Kf}, \mathrm{Ks}$, and ave $\mathrm{K}$ between the VERION and OPD III devices were $0.55 \pm 0.44 \mathrm{D}, 0.58 \pm 0.50 \mathrm{D}$, and $0.50 \pm 0.41 \mathrm{D}$, respectively, with statistically significant differences observed for all values $(t=-2.769, P<0.05$; $t=-2.377$, $P<0.05$; and $t=-2.643, P<0.05$, respectively).

\section{Axis analysis}

The corneal astigmatism axis for VERION was compared to those for LenStar, AL-Scan (2.4 mm), and OPD III. Table 1 lists the mean Kf axis for the devices. KR-8800 and VERION had large angle axis differences of $\sim 3^{\circ}$. LenStar was closest

Table 2 The percentage of eyes for corneal cylinder differences between the VERION Reference Unit and other devices

\begin{tabular}{|c|c|c|c|c|}
\hline \multirow[t]{2}{*}{ Eye $N=115$} & $\begin{array}{l}\text { VERION - } \\
\text { LenStar }\end{array}$ & $\begin{array}{l}\text { VERION - AL-Scan } \\
(2.4 \mathrm{~mm})\end{array}$ & VERION - OPD III & VERION - KR-8800 \\
\hline & n (\%) & n (\%) & n (\%) & n (\%) \\
\hline$>0.75 \mathrm{D}$ & $8(7)$ & $7(7)$ & $6(5)$ & $6(5)$ \\
\hline $0.50-0.75 \mathrm{D}$ & $13(11)$ & $10(9)$ & $15(13)$ & $16(14)$ \\
\hline $0.25-0.50 \mathrm{D}$ & $31(27)$ & $24(21)$ & $39(34)$ & $37(32)$ \\
\hline$<0.25 \mathrm{D}$ & $63(55)$ & $74(64)$ & $55(48)$ & $56(49)$ \\
\hline
\end{tabular}




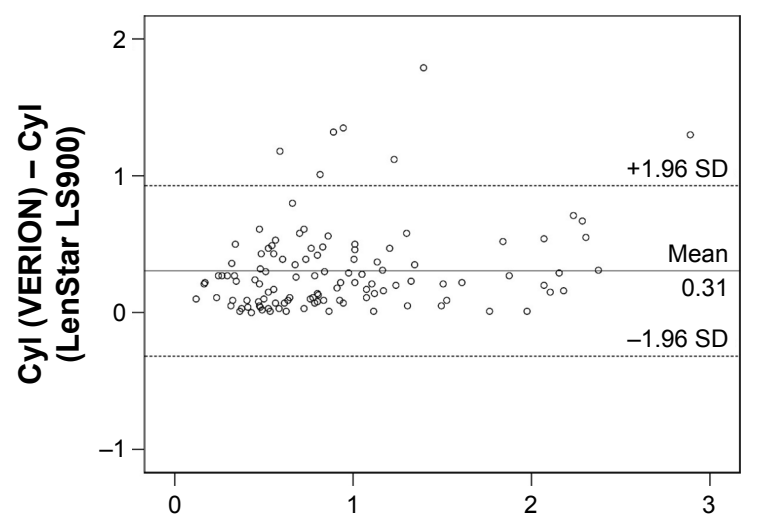

(Cyl (VERION) + Cyl (LenStar LS900))/2

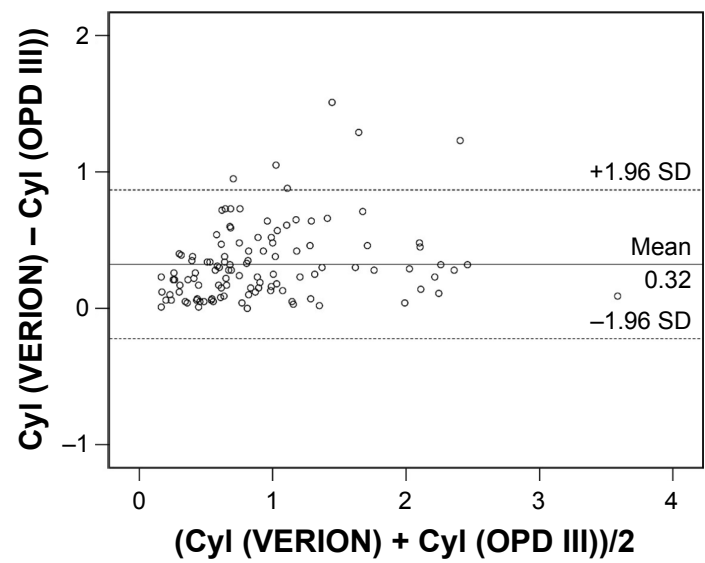

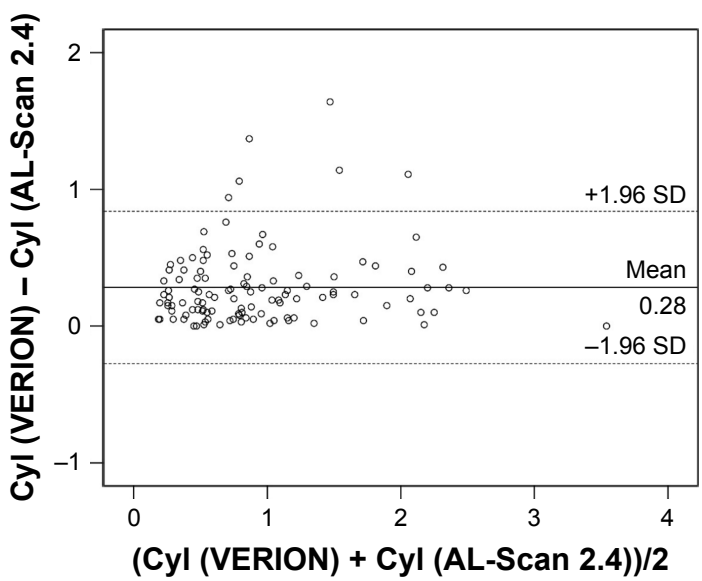

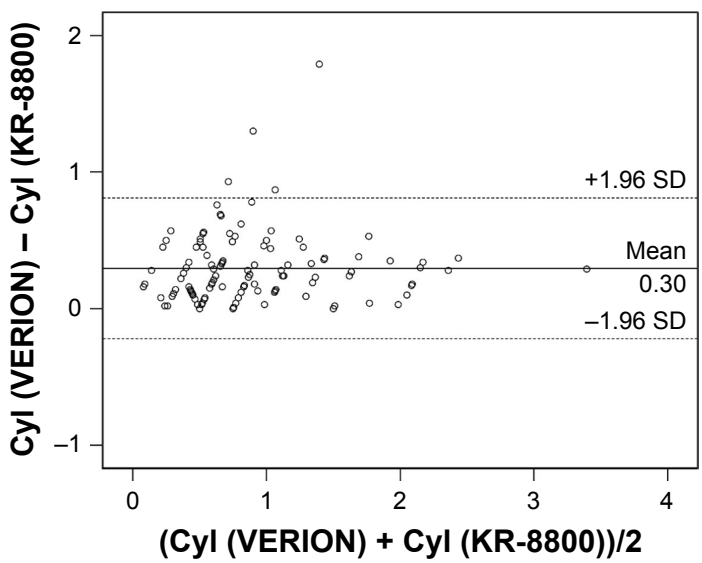

Figure 2 Bland-Altman plot comparing the corneal cylinder obtained with VERION Reference Unit and 4 other devices (LenStar, AL-Scan [2.4 mm], OPD III, and KR-8800).

Notes: The $95 \%$ LOAs ranged from $-0.32 \mathrm{D}$ to $0.93 \mathrm{D},-0.28 \mathrm{D}$ to $0.84 \mathrm{D},-0.22 \mathrm{D}$ to $0.87 \mathrm{D}$, and $-0.22 \mathrm{D}$ to $0.8 \mathrm{I} \mathrm{D}$, respectively. Dotted lines $\pm \mathrm{I} .96 \mathrm{SD}$.

Abbreviations: LOAs, limits of agreement; SD, standard deviation.

to VERION in the mean astigmatism axis. We found no statistically significant differences in the mean values using one-sample $t$-test.

Table 4 shows the variation in the astigmatic flat axis obtained from different devices. The astigmatic axis measurements differed by $<10^{\circ}$, ranging from $52 \%$ to $61 \%$. AL-Scan showed the smallest difference from VERION with 70 eyes $(61 \%)$ in $<10^{\circ}$ group, and KR-8800 was 60 eyes $(52 \%)$ but showed 26 eyes $(23 \%)$ in $10^{\circ}-20^{\circ}$ group.
The corneal astigmatic axis Bland-Altman plot for the devices showed only a low to moderate level of agreement between the 2 values. The 95\% LOAs are presented in Figure 3. The largest width for the $95 \%$ LOA in astigmatic axis measurement $\left(93.02^{\circ}\right)$ was between VERION and KR-8800.

\section{Analysis of $\mathrm{CV}$ values}

According to the results of the differences in K-reading calculations, $\mathrm{CV}$ (SD/mean) ${ }^{18}$ was compared between the

Table 3 Measurement differences of flattest and steepest keratometry between the VERION and the other devices

\begin{tabular}{lllll}
\hline Parameter & $\begin{array}{l}\text { VERION vs } \\
\text { LenStar }\end{array}$ & $\begin{array}{l}\text { VERION vs } \\
\text { AL-Scan }(2.4 \mathbf{~ m m})\end{array}$ & $\begin{array}{l}\text { VERION vs } \\
\text { OPD III }\end{array}$ & $\begin{array}{l}\text { VERION vs } \\
\text { KR-8800 }\end{array}$ \\
\hline Kf (D) & $0.22 \pm 0.47$ & $0.20 \pm 0.46$ & $0.18 \pm 0.45^{*}$ & $0.21 \pm 0.47$ \\
P-value; $t$ & $0.17 ;-1.37$ & $0.14 ;-1.48$ & $0.01 ;-2.77$ & $0.12 ;-1.58$ \\
Ks (D) & $0.19 \pm 0.42$ & $0.15 \pm 0.41$ & $0.17 \pm 0.38^{*}$ & $0.25 \pm 0.42$ \\
P-value; $t$ & $0.26 ;-1.13$ & $0.28 ;-1.08$ & $0.02 ;-2.38$ & $0.08 ;-1.77$ \\
Ave K (D) & $0.20 \pm 0.37$ & $0.17 \pm 0.36$ & $0.18 \pm 0.35 *$ & $0.23 \pm 0.40$ \\
P-value; $t$ & $0.21 ;-1.27$ & $0.19 ;-1.31$ & $0.01 ;-2.64$ & $0.09 ;-1.71$
\end{tabular}

Note: *Statistically significant difference $(P<0.05$, one-sample two-tailed $t$-test).

Abbreviations: $\mathrm{K}$, keratometry; Kf, flattest keratometry; Ks, steepest keratometry; ave $\mathrm{K}$, average keratometry. 
Table 4 The variation of astigmatic flat axis obtained from different devices

\begin{tabular}{|c|c|c|c|c|}
\hline Eye $N=115$ & VERION - LenStar & VERION - AL-Scan & VERION - OPD III & VERION - KR-8800 \\
\hline & n (\%) & n (\%) & n (\%) & n (\%) \\
\hline$<10^{\circ}$ & $62(54)$ & $70(6 \mathrm{I})$ & $62(54)$ & $60(52)$ \\
\hline $10^{\circ}-20^{\circ}$ & $28(24)$ & $22(19)$ & $21(18)$ & $26(23)$ \\
\hline$>10^{\circ}$ & $34(30)$ & $23(20)$ & $32(28)$ & $29(25)$ \\
\hline
\end{tabular}

devices. Table 5 shows the differences in $\mathrm{CV}$ values between VERION and the other devices. CVs for OPD III were lower than for the other devices. Astigmatism axis (Kf and $\mathrm{Ks}$ axes) $\mathrm{CVs}$ were larger than those for keratometric power (Kf, Ks, corneal astigmatism, and ave $\mathrm{K}$ ). However, astigmatism axis CVs demonstrated a small range from 1.27 to 1.34 , indicating the high accuracy of astigmatism axis measurements using the evaluated devices.

\section{Analysis of correlation coefficients}

All the parameters measured with the other devices were found to be significantly and moderately to highly correlated with those measured using the VERION system $(P<0.05)$. Keratometric power values measured with each device were highly correlated ( $r=0.91-0.95)$. Corneal astigmatism $(\mathrm{Kf}-\mathrm{Ks})$ values recorded with each device were also highly correlated ( $r=0.79-0.82)$, with the exception of the LenStar device, which demonstrated a moderate correlation with measurements obtained using the VERION system $(r=0.75)$. Astigmatism axis values were moderately correlated, with a tendency for greater $\mathrm{Ks}$ axis values than $\mathrm{Kf}$ axis values. Correlation coefficients for the $\mathrm{Ks}$ axis for each device (LenStar, AL-Scan [2.4 mm], AL-Scan [3.3 mm], OPD III,
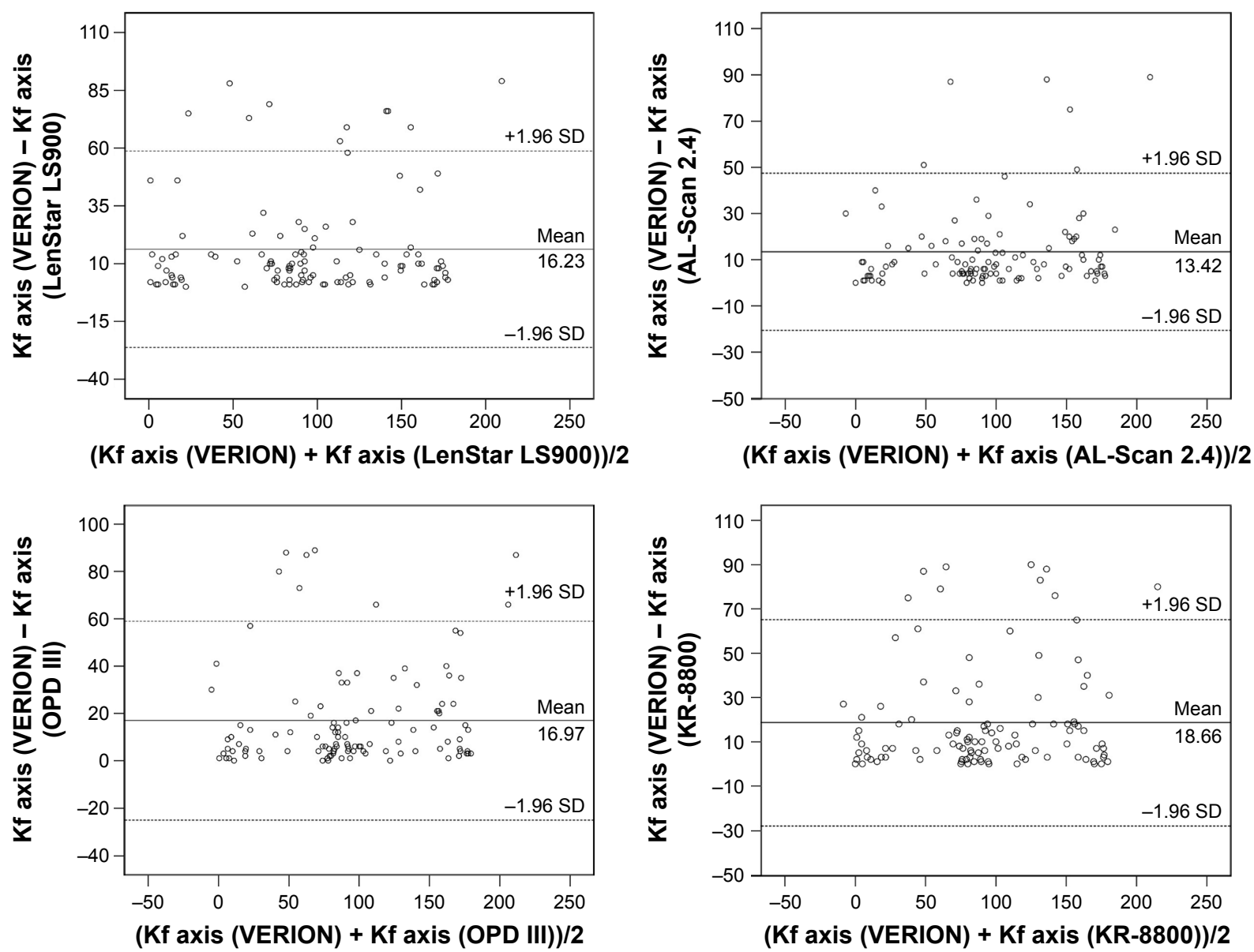

Figure 3 Bland-Altman plot comparing the corneal astigmatic axis obtained using VERION Reference Unit and 4 other devices (LenStar, AL-Scan [2.4 mm], OPD III, and KR-8800).

Notes: The $95 \%$ LOAs ranged from $-26.25^{\circ}$ to $58.7 I^{\circ},-20.61^{\circ}$ to $47.44^{\circ},-25.03^{\circ}$ to $58.98^{\circ}$, and $-27.85^{\circ}$ to $65.17^{\circ}$. Dotted lines $\pm 1.96 \mathrm{SD}$.

Abbreviations: LOAs, limits of agreement; Kf, flattest keratometry; SD, standard deviation. 
Table $5 \mathrm{CV}$ values for differences between the VERION Reference Unit and other devices

\begin{tabular}{lllll}
\hline $\begin{array}{l}\text { Parameters } \\
\text { (eye } \mathbf{N}=\text { I I 5) }\end{array}$ & LenStar & $\begin{array}{l}\text { AL-Scan } \\
\mathbf{( 2 . 4} \mathbf{~ m m})\end{array}$ & OPD III & KR-8800 \\
\hline Kf & 0.94 & 0.96 & 0.86 & 0.95 \\
Ks & 0.85 & 0.89 & $0.8 I$ & 0.83 \\
Kf-Ks & 1.04 & 1.01 & 0.86 & 0.89 \\
Kf and Ks axis & 1.34 & 1.29 & 1.25 & 1.27 \\
(astigmatism axis) & & & & \\
Ave K & 0.84 & 0.86 & 0.82 & 0.86 \\
\hline
\end{tabular}

Abbreviations: $\mathrm{CV}$, coefficients of variation; $\mathrm{K}$, keratometry; $\mathrm{Kf}$, flattest keratometry; Ks, steepest keratometry; ave K, average keratometry.

and KR-8800) were as follows: $r=0.47,0.58,0.49,0.45$, and 0.49 , respectively; $\mathrm{Kf}$ axis: $r=0.61,0.55,0.47,0.47$, and 0.34 , respectively.

\section{Discussion}

Postoperative visual acuity has been shown to be associated with the accuracy of keratometry measurements prior to cataract surgery, ${ }^{19}$ with astigmatism overcorrection or large degrees of axis misalignment known to induce patient discomfort. ${ }^{20}$ Viestenzet et $\mathrm{al}^{3}$ reported that astigmatism correction decreased by $3.33 \%$ for each degree of toric IOL rotation. Further, patients with $30^{\circ}$ toric IOL rotation had obvious residual astigmatism, and astigmatism was higher in those with $\mathrm{IOL}$ axis rotation $>30^{\circ}$. In this study, the mean corneal astigmatism was $0.96 \pm 0.58 \mathrm{D}$, ranging from $0.07 \mathrm{D}$ to $3.54 \mathrm{D}$. These results are similar to those reported by Hoffmann and Hütz. ${ }^{21}$ Ferrer-Blasco et $\mathrm{al}^{2}$ found that $64.4 \%$ and $22.2 \%$ of cataract patients had $(0.25-1.25) \mathrm{D}$ and $>1.25 \mathrm{D}$ corneal astigmatism, respectively. In our study, the Kf, Ks, and corneal astigmatism values obtained with the VERION system were slightly greater than those obtained with other devices. The recent study by Mueller et $\mathrm{al}^{22}$ reported similar results in the comparison of VERION and LenStar LS900 (OLCR device), and Schultz et al ${ }^{23}$ also found that the Ks values of VERION were slightly greater than those of AL-Scan and OPD III.

The evaluation of the VERION system for residual astigmatism management with toric IOL surgery has been reported, ${ }^{24}$ and the use of a LenSx femtosecond laser system platform combined with the VERION system was also reported..$^{13}$ However, the comparability, reliability, and repeatability of pre-surgery corneal astigmatism measurements using the VERION system have yet to be fully evaluated (Google Scholar, as of April 5, 2017). ${ }^{10}$

In this study, corneal data measurements with each device based on different techniques and calculations are thought to result in different $\mathrm{K}$-values measurements. Hashemi et $\mathrm{al}^{25}$ compared the LenStar, auto kerato-refractometer, and Pentacam-Scheimpflug technology anterior segment imaging systems and demonstrated variations in K-values obtained from each system. In this study, significant differences in $\mathrm{Kf}$ axis, $\mathrm{Ks}$, and ( $\mathrm{Kf}-\mathrm{Ks}$ ) values were observed between the auto kerato-refractometer and VERION systems. In particular, the difference in the mean $\mathrm{Kf}$ axis values between the auto kerato-refractometer and VERION systems was $\sim 10.70^{\circ}$. This was greater than the differences between VERION and the other devices, which ranged from $5^{\circ}$ to $6^{\circ}$. The auto kerato-refractometer, KR-8800, has demonstrated convenience and utility in clinical practice but is only considered appropriate for regular corneal astigmatism measurements prior to toric IOL implantation. In other circumstances, this method may lose more data from peripheral corneal regions. Steepening changes to the corneal surface may also be due to keratoconus or high regular astigmatism. Only a proportion of irregular astigmatism cases may present as central cornea steepening, clinically limiting the KR-8800 system in these situations. ${ }^{2}$ Another article reported similar differences between VERION and auto kerato-refractometer. ${ }^{26}$

The IOL master (Carl Zeiss Meditec AG, Jena, Germany) utilizes automated keratometry, similar to the VERION, LenStar, and AL-Scan devices. The IOL master uses 6 light spots projected on to the cornea in a hexagonal pattern, with a range from $\sim 2.4 \mathrm{~mm}$ to $2.5 \mathrm{~mm}$. Further, this system calculates the average of 3 consecutive measurements, which integrate a number of functions including K-values. The SRK/T formula-based toric IOL power calculations for the system are considered comparable to those for other devices. ${ }^{7}$ Many comparative studies have reported corneal astigmatism measurements using the IOL master. ${ }^{7,10,25}$ In a recent study, Visser et $\mathrm{al}^{10}$ evaluated the SMI Reference Unit (SensoMotoric Instruments, Boston, MA, USA) for surgery image integration, similar to the VERION Reference Unit technique. They found that the SMI Reference Unit, LenStar, and IOL master devices all had comparable reliability in providing accurate K-values measurements. Additionally, Nemeth et $\mathrm{al}^{27}$ reported that VERION has high repeatability and agreement with the IOL master.

Using the Placido disk image from OPD III, precise data obtained from the anterior corneal surface curvature has no relationship to the axis and reference points of automated keratometry. OPD III can quantify irregular astigmatism. ${ }^{28}$ This study demonstrated significant differences in keratometric power (Kf, Ks, and ave $\mathrm{K}$ ) between OPD III and VERION $(P<0.05)$, with high correlations (correlation coefficients of 
0.91, 0.93, and 0.94, respectively). However, no differences in corneal astigmatism axis values were observed. Both corneal topography and automated keratometry were found to be highly accurate in measuring the corneal astigmatism axis, corroborating a previous study by Mao et al. ${ }^{9}$ Lee et al ${ }^{19}$ reported that measured corneal K-values tended to be overestimated by Placido-based videokeratography. However, this finding is in contrast to the results of this study, in which OPD III mean keratometric Kf, Ks, and ave $\mathrm{K}$ parameters were smaller than values measured with other automated keratometers (such as VERION, LenStar, AL-Scan [2.4 mm], and KR-8800), which ranged from $\sim 0.2 \mathrm{D}$ to $0.18 \mathrm{D}, 0.02 \mathrm{D}$ to $0.17 \mathrm{D}$, and $0.02 \mathrm{D}$ to $0.17 \mathrm{D}$, respectively. In addition, OPD III had the smallest CV of any K-values for differences compared to VERION (Table 5). This discrepancy is attributable to the different measurement techniques and measuring field; however, these devices may still have utility in obtaining reference values.

When comparing the AL-Scan $2.4 \mathrm{~mm}$ and $3.3 \mathrm{~mm}$ $\mathrm{K}$-reading values, the mean differences in central corneal and paracentral corneal zones were $\sim 0.02-0.04 \mathrm{D}$. Regarding comparisons between the AL-Scan and VERION devices, the difference in values from the paracentral corneal zone (AL-Scan $3.3 \mathrm{~mm}$ ) was $\sim 1^{\circ}$ greater than the difference in the central corneal zone values (AL-Scan $2.4 \mathrm{~mm}$ ). In previous studies, Kaswin et $\mathrm{al}^{7}$ reported no difference in K-values between IOL master and either AL-Scan $2.4 \mathrm{~mm}$ or $3.3 \mathrm{~mm}$ measurements. Huang et $\mathrm{al}^{8}$ further found a high comparability in K-values between IOL master and AL-Scan, with more accurate $\mathrm{K}$-values obtained from the $2.4 \mathrm{~mm}$ zone for IOL power calculations.

In addition, $\mathrm{Ho}_{\mathrm{e}} \mathrm{al}^{29}$ reported that $\sim 10 \%$ of cataract patients had $>1.00 \mathrm{D}$ in corneal astigmatism, with a difference between the anterior surface and total corneal astigmatism of $>0.50$ D. Further, the authors suggested that clinicians should consider total corneal astigmatism and axis changes following toric IOL implantation in order to optimize postoperative visual quality.

This study has 2 limitations. First, morphological changes of the total corneal surface were not evaluated and corneal pachymetry measurements can provide more accurate corneal data than that in this study. ${ }^{30}$ Second, although the VERION system can provide astigmatism axis data and integrate these data with anterior segment imaging, the customizable "horizontal line" reference point is the most likely reason for the differences observed with other devices. Although the default measurement zones for VERION and the other devices have a similar diameter, mean K-reading value differences were largely similar, likely due to the different characteristics of the devices. The results of the present comparisons indicate that preoperative keratometry measurements should not be dependent on a single device. Rather, a combination of different devices provides surgeons with more complete reference data. ${ }^{31}$ As the VERION Reference Unit is still a relatively novel device, further studies combining evaluations of corneal aberrations, IOL power calculation values, and postoperative visual outcomes are required.

\section{Conclusion}

This study demonstrated moderate to high correlations for all parameters measured using VERION compared to those measured using other devices. No differences were observed between the VERION Reference Unit, AL-Scan, and LenStar devices, which are all automated keratometers that rely on the projection of light onto the corneal surface in order to obtain K-values measurements. Values obtained using the AL-Scan $2.4 \mathrm{~mm}$ zone method and VERION were particularly similar. The VERION, AL-Scan, LenStar, and OPD III devices allow accurate measurement of astigmatism axis values, with each biometer capable of providing highly accurate data for presurgery planning. As more severe peripheral corneal shape deformations or irregular astigmatism may affect measurement results, further corneal topography and pachymetry measurements may be required to obtain reference values in such cases. By understanding the utility and performance of different devices, surgeons can select the most appropriate combination of devices for the evaluation of individual patients and clinical applications.

\section{Acknowledgments}

We thank the Zhongli Branch of the Universal Eye Center for providing a research platform. The authors alone are responsible for the content and writing of the paper.

\section{Disclosure}

The authors report no conflicts of interest in this work.

\section{References}

1. Elbaz U, Barkana Y, Gerber Y, Avni I, Zadok D. Comparison of different techniques of anterior chamber depth and keratometric measurements. Am J Ophthalmol. 2007;143(1):48-53.

2. Ferrer-Blasco T, Montés-Micó R, Peixoto-de-Matos SC, GonzálezMéijome JM, Cerviño A. Prevalence of corneal astigmatism before cataract surgery. J Cataract Refract Surg. 2009;35(1):70-75.

3. Viestenz A, Seitz B, Langenbucher A. Evaluating the eye's rotational stability during standard photography: effect on determining the axial orientation of toric intraocular lenses. J Cataract Refract Surg. 2005;31(3): $557-561$ 
4. Visser N, Bauer NJ, Nuijts RM. Toric intraocular lenses: historical overview, patient selection, IOL calculation, surgical techniques, clinical outcomes, and complications. J Cataract Refract Surg. 2013;39(4): 624-637.

5. Borasio E, Mehta JS, Maurino V. Surgically induced astigmatism after phacoemulsification in eyes with mild to moderate corneal astigmatism: temporal versus on-axis clear corneal incisions. J Cataract Refract Surg. 2006;32(4):565-572.

6. Wang X, Dong J, Wu Q. Comparison of anterior corneal curvature measurements using a galilei dual scheimpflug analyzer and topcon auto kerato-refractometer. J Ophthalmol. 2014;2014:140628.

7. Kaswin G, Rousseau A, Mgarrech M, Barreau E, Labetoulle M. Biometry and intraocular lens power calculation results with a new optical biometry device: comparison with the gold standard. J Cataract Refract Surg. 2014;40(4):593-600.

8. Huang J, Savini G, Li J, et al. Evaluation of a new optical biometry device for measurements of ocular components and its comparison with IOLMaster. Br J Ophthalmol. 2014;98(9):1277-1281.

9. Mao X, Savini G, Zhuo Z, et al. Repeatability, reproducibility, and agreement of corneal power measurements obtained with a new corneal topographer. J Cataract Refract Surg. 2013;39(10):1561-1569.

10. Visser N, Berendschot TT, Verbakel F, de Brabander J, Nuijts RM. Comparability and repeatability of corneal astigmatism measurements using different measurement technologies. J Cataract Refract Surg 2012;38(10):1764-1770.

11. Shirayama M, Wang L, Weikert MP, Koch DD. Comparison of corneal powers obtained from 4 different devices. Am J Ophthalmol. 2009; 148(4):528.e1-535.e1.

12. Rose LT, Moshegov CN. Comparison of the Zeiss IOLMaster and applanation A-scan ultrasound: biometry for intraocular lens calculation. Clin Experiment Ophthalmol. 2003;31(2):121-124.

13. Reggiani-Mello G, Krueger RR. Comparison of commercially available femtosecond lasers in refractive surgery. Expert Rev Ophthalmol. 2011;6:55-65.

14. Lege B, Haigis W. Laser interference biometry versus ultrasound biometry in certain clinical conditions. Graefes Arch Clin Exp Ophthalmol. 2004;242(1):8-12.

15. Cruysberg LP, Doors M, Verbakel F, Berendschot TT, De Brabander J, Nuijts RM. Evaluation of the Lenstar LS 900 non-contact biometer Br J Ophthalmol. 2010;94(1):106-110.

16. Holzer MP, Mamusa M, Auffarth GU. Accuracy of a new partial coherence interferometry analyser for biometric measurements. $\mathrm{Br} J$ Ophthalmol. 2009;93(6):807-810.

17. Bland JM, Altman D. Statistical methods for assessing agreement between two methods of clinical measurement. Lancet. 1986;327(8476): $307-310$.
18. Chinn S. The assessment of methods of measurement. Stat Med. 1990; 9(4):351-362.

19. Lee AC, Qazi MA, Pepose JS. Biometry and intraocular lens power calculation. Curr Opin Ophthalmol. 2008;19(1):13-17.

20. Ermiş SS, İnan ÜÜ, Öztürk F. Surgically induced astigmatism after superotemporal and superonasal clear corneal incisions in phacoemulsification. J Cataract Refract Surg. 2004;30(6):1316-1319.

21. Hoffmann PC, Hütz WW. Analysis of biometry and prevalence data for corneal astigmatism in 23,239 eyes. J Cataract Refract Surg. 2010; 36(9):1479-1485.

22. Mueller A, Thomas BC, Auffarth GU, Holzer MP. Comparison of a new image-guided system versus partial coherence interferometry, Scheimpflug imaging, and optical low-coherence reflectometry devices: keratometry and repeatability. J Cataract Refract Surg. 2016;42(5):672-678.

23. Schultz M, Oberheide U, Kermani O. Comparability of an image-guided system with other instruments in measuring corneal keratometry and astigmatism. J Cataract Refract Surg. 2016;42(6):904-912.

24. Solomon K. Initial clinical outcomes with image-guided system for surgical planning and digital alignment of patients with toric IOL. Paper presented at: 2015 ASCRS ASOA Symposium and Congress; United States, San Diego; 2015.

25. Hashemi H, Asgari S, Miraftab M, Emamian MH, Shariati M, Fotouhi A. Agreement study of keratometric values measured by Biograph/LENSTAR, auto-kerato-refractometer and Pentacam: decision for IOL calculation. Clin Exp Optom. 2014;97(5):450-455.

26. Asena L, Güngör SG, Akman A. Comparison of keratometric samples obtained by the Verion Image Guided System with optical biometry and auto-keratorefractometer. Int Ophthalmol. 2017;37(2):391-399.

27. Nemeth G, Szalai E, Hassan Z, Lipecz A, Berta A, Modis L Jr. Repeatability data and agreement of keratometry with the VERION system compared to the IOLMaster. J Refract Surg. 2015;31(5):333-337.

28. Read SA, Collins MJ, Carney LG, Franklin RJ. The topography of the central and peripheral cornea. Invest Ophthalmol Vis Sci. 2006;47(4): 1404-1415.

29. Ho JD, Tsai CY, Liou SW. Accuracy of corneal astigmatism estimation by neglecting the posterior corneal surface measurement. Am J Ophthalmol. 2009;147(5):788-795, 795.e1-795.e2.

30. Koch DD, Jenkins RB, Weikert MP, Yeu E, Wang L. Correcting astigmatism with toric intraocular lenses: effect of posterior corneal astigmatism. J Cataract Refract Surg. 2013;39(12):1803-1809.

31. Davison JA, Potvin R. Refractive cylinder outcomes after calculating toric intraocular lens cylinder power using total corneal refractive power. Clin Ophthalmol. 2015;9:1511.
Clinical Ophthalmology

\section{Publish your work in this journal}

Clinical Ophthalmology is an international, peer-reviewed journal covering all subspecialties within ophthalmology. Key topics include: Optometry; Visual science; Pharmacology and drug therapy in eye diseases; Basic Sciences; Primary and Secondary eye care; Patient Safety and Quality of Care Improvements. This journal is indexed on Submit your manuscript here: http://www.dovepress.com/clinical-ophthalmology-journal

\section{Dovepress}

PubMed Central and CAS, and is the official journal of The Society of Clinical Ophthalmology (SCO). The manuscript management system is completely online and includes a very quick and fair peer-review system, which is all easy to use. Visit http://www.dovepress.com/ testimonials.php to read real quotes from published authors. 